\title{
PRÁTICAS DE SUSTENTABILIDADE NA CONSTRUÇÃO CIVIL: UM ESTUDO EM EMPRESAS CONSTRUTORAS DE EDIFICAÇÕES
}

\section{FLADIMIR FERNANDES DOS SANTOS}

Doutor em Engenharia e Gestão do conhecimento, Universidade Federal de Santa Catarina - UFSC, Brasil. Professor, Universidade Federal do Pampa - UNIPAMPA, Brasil.

fladimirfernandes@gmail.com

\section{Djeisse Franciele Peiter Sehen}

Mestre em Engenharia de Minas, Metalúrgica e de Materiais, Universidade Federal do Rio Grande do Sul UFRGS, Brasil.

djeisse.eng@gmail.com

\section{Marco Aurélio Batista de SOUSA}

Pós-Doutor em Ciências Contábeis, Universidade Federal de Uberlândia - UFU, Brasil.

Professor, Universidade Federal de Mato Grosso do Sul - UFSM, Brasil.

mcbsousa@bol.com.br

\section{NiRLENE FERnANDES CECHIN}

Doutora em Engenharia Florestal, Universidade Federal de Santa Maria - UFSM, Brasil.

nirlenecechin@unipampa.edu.br

\section{Resumo}

Este trabalho teve como objetivo verificar se as práticas sustentáveis adotadas por algumas empresas, na construção de edifícios sustentáveis, estão em conformidade com os três elementos que compõem o pilar do desenvolvimento sustentável, a partir da aplicação de um questionário aos responsáveis técnicos pela área de gerenciamento de projetos e execução de obras de seis empresas construtoras de edificações, localizadas na região Sul do Brasil. E, assim, foi possivel perceber que, nestas empresas existem algumas soluções sustentáveis, como por exemplo: qualidade urbana, soluções de paisagismo, ventilação e iluminação natural de banheiros e áreas comuns, utilização de componentes pré-fabricados, medição individualizada nas edificações e gestão de resíduos de construção e demolição. Entretanto, ainda existe espaço para a possibilidade de se implementar melhorias, executando ações que sejam ambientalmente responsáveis, socialmente justas e economicamente viáveis.

Palavras-chave: sustentabilidade, práticas sustentáveis, sustentabilidade na indústria de edificações, desenvolvimento sustentável. 


\title{
SUSTAINABILITY PRACTICES IN CIVIL CONSTRUCTION: A STUDY IN BUILDING CONSTRUCTION COMPANIES
}

\begin{abstract}
The objective of this study was to verify if the sustainable practices, adopted by some companies in the construction of sustainable buildings, are in conformity with the three elements that make up the pillar of sustainable development, through the application of a survey to the technical responsible by the works project and execution management area of six construction companies located in the Brazilian Southern region. So, it was possible to realize that in these companies there are some sustainable solutions, such as: urban quality, landscaping solutions, ventilation and natural lighting of bathrooms and common areas, usage of prefabricated components, individualized measurement in buildings and construction and demolition waste management. However, there is still a gap for the possibility of implementing improvements, executing actions that are environmentally responsible, socially fair and economically viable.
\end{abstract}

Keywords: Sustainability. Sustainable practices. Sustainability in the building industry. sustainable development.

\section{PRÁCTICAS DE SOSTENIBILIDAD EN LA CONSTRUCCIÓN CIVIL: UN ESTUDIO EN EMPRESAS CONSTRUCTORAS DE EDIFICACIONES}

\begin{abstract}
Resumen
Este trabajo tuvo como objetivo verificar si las prácticas sostenibles adoptadas por algunas empresas en la construcción de edificios sostenibles están en conformidad con los tres elementos que componen el pilar del desarrollo sostenible, a partir de la aplicación de un cuestionario a los responsables técnicos por el área de desarrollo gestión de proyectos y ejecución de obras de seis empresas constructoras de edificaciones, ubicadas en la región sur de Brasil. Y, así, fue posible percibir que, en estas empresas existen algunas soluciones sostenibles, como, por ejemplo: calidad urbana, soluciones de paisajismo, ventilación e iluminación natural de baños y áreas comunes, utilización de componentes prefabricados, medición individualizada en las edificaciones y gestión de residuos de construcción y demolición. Sin embargo, todavía existe espacio para la posibilidad de implementar mejoras, ejecutando acciones que sean ambientalmente responsables, socialmente justas y económicamente viables.

Palabras clave: sostenibilidad, prácticas sostenibles, sostenibilidad en la industria de edificaciones, desarrollo sostenible.
\end{abstract}




\section{INTRODUÇÃO}

O crescimento econômico, alavancado pela industrialização e pela desordenada exploração de recursos naturais, tem colocado "em risco a manutenção das condições favoráveis à existência de vida no planeta" (Stumpf, Theis \& Schreiber, 2018, p. 230). Diante disso, a "busca pelo equilíbrio entre os aspectos ambientais, sociais e econômicos é um desafio para a sobrevivência dos negócios e tem levado as empresas a adotarem iniciativas voltadas para a sustentabilidade" (Hepper, Hansen \& Santos, 2016, p. 98).

Nos últimos anos houve um aumento considerável na consciência ambiental global. Isso se deve principalmente aos problemas ambientais emergentes, como mudanças climáticas, problemas com demanda de energia e água, perda de habitat dos animais e desmatamento. O surgimento dessas questões e a crescente conscientização resultaram em esforços concentrados em encontrar soluções e o resultado desses esforços evidenciou que havia a necessidade de abraçar e implementar requisitos de sustentabilidade e desenvolvimento sustentável (Elmualim \& Alp, 2016).

Neste sentido, é possivel perceber que existiu uma progressiva conscientização da sociedade diante da escassez dos recursos naturais, da necessidade da inclusão de práticas com menor impacto ambiental e da busca por um modelo de desenvolvimento sustentável (Motta, 2009). De acordo com Souza (2007), as empresas passaram a dar importância e a observar o impacto que as suas atividades causavam ao meio ambiente, a partir das exigências feitas pela sociedade. Particularmente no setor da construção civil, tais requisitos se acentuam devido ao alto impacto ambiental e social das atividades que este setor atua, com a fabricação de materiais, no desenvolvimento de projetos e nas construções e operações de edificações.

O aumento da população humana requer mais edifícios que exigem mais uso de recursos. Essa tendência tem um impacto negativo no meio ambiente, nas questões econômicas e sociais, afetando a qualidade de vida das gerações atuais e futuras (Atombo, Dzantor \& Agbo, 2015). No setor da construção civil nota-se que ficou evidente a necessidade de adequação às agendas de sustentabilidade, no qual foram desenvolvidos métodos avaliativos dos impactos ambientais das edificações. "Estes métodos são importantes porquê sem a determinação de parâmetros e metas não há como verificar o atendimento às questões de sustentabilidade a que os países estão sujeitos" (Mendes, Farias \& Tavares, 2014, p. 195).

Assim, "a certificação da sustentabilidade de edifícios já foi criada no exterior há algum tempo e no Brasil há interesse crescente no assunto" (Corsani, Kalbusch \& Ramos, 2010, p. 4). Estados Unidos, Canadá, Austrália, Japão, China, entre outros países da Europa, investiram nesses sistemas de certificação com base em critérios e indicadores de desempenho ambiental. 0 impulso para 0 desenvolvimento de tais sistemas surgiu a partir da constatação de que, "mesmo os países que acreditavam dominar os conceitos de projeto ecológico, não possuíam meios para verificar quão "verdes" eram de fato os seus edifícios" (Silva, 2003).

O Brasil deu alguns passos rumo ao desenvolvimento sustentável, aderindo a metodologias de avaliações de edifícios. Porém, é necessário observar que o projeto e a construção de edifícios sustentáveis exigem que as empresas possuam uma organização diferente, com mudanças que abrangem desde a organização de documentos e atualizações normativas, em grandes proporções, até o treinamento dos profissionais e dos operários no canteiro de obras (Salgado, Chatelet \& Fernandez, 2012).

Sendo um assunto que está cada vez mais em pauta, o país entende da necessidade de reflexão sobre a preservação dos recursos naturais, da busca pelo equilíbrio entre os aspectos ambientais, sociais e econômicos. Os temas sustentabilidade e meio ambiente vêm ocasionando o interesse de chefes de estados, de organizações internacionais e de empresas de todos os portes, visando a

OS, Organizações e Sustentabilidade, 8(2), p. 34-53, Londrina, PR, jun./dez. 2020.

ISSN 2318-9223, http://www.uel.br/revistas/uel/index.php/ros/issue/view/1683/showToc 
maior conscientização da sociedade no que diz respeito à necessidade do uso sustentável dos recursos naturais, tanto em relação aos aspectos ambientais, quanto ao que diz respeito aos aspectos sociais e econômicos (Sebrae, 2012).

Percebe-se, pelo estudo realizado por Teixeira, Zamberlam, Santos \& Gomes (2016, p. 58), em três empresas, que, mesmo demonstrando comprometimento com a agenda de sustentabilidade, duas empresas ainda o estão fazendo de forma incipiente, ou superficial. Para os supracitados autores, mesmo que existam esforços genuínos para assumir processos de mudança sustentável, as capacidades adaptativas das duas empresas "são insuficientemente desenvolvidas e, portanto, a probabilidade de elas contribuírem para produzir impactos na solução de tensões sociais e ambientais ainda é reduzida".

Como a realidade das empresas é bastante distinta, nesta pesquisa entende-se como necessário realizar estudos que abordem o uso de práticas sustentáveis em empresas brasileiras construtoras de edificações. Diante do exposto, o objetivo deste trabalho foi verificar se as práticas adotadas no Brasil, por algumas empresas na construção de edifícios sustentáveis, estão em conformidade com os três elementos que compõem o pilar do desenvolvimento sustentável.

\section{DESENVOLVIMENTO SUSTENTÁVEL}

De acordo com Meadows, Meadows e Randers (2004), durante séculos o mundo enfrentou diversas revoluções, como a agrícola e a industrial, e todas elas mudaram a forma da população interagir com os sistemas existentes. A revolução agrícola trouxe à tona conceitos de propriedade de terra, feudalismo, riqueza, profissão, poder, dinheiro e cidades. No período decorrente da revolução industrial a população global aumentou significativamente e trouxe máquinas, estradas, ferrovias combustão, chaminés, fábricas e grandes áreas urbanas (Mihelcic \& Zimmerman, 2012).

Tal desenvolvimento urbano e industrial, por não conhecer limites, ocorreu de maneira desordenada, sem planejamento algum e com crescentes niveis de degradação e poluição do meio ambiente (Braga et al., 2005). A partir deste momento, nota-se a ocorrência de uma sucessão de eventos que começaram a abranger discussões sobre a sustentabilidade.

Na visão de Mihelcic e Zimmerman (2012), a maioria das definições de sustentabilidade incorpora três elementos, considerados o pilar de sustentabilidade, que são o meio ambiente, a economia e a sociedade. 0 termo desenvolvimento sustentável vem sendo utilizado para unir estes elementos.

A World Commission on Environment and Development (1987) aborda o desenvolvimento sustentável como uma ideia de garantir uma melhor qualidade de vida para todas as pessoas, no presente e para as futuras gerações, por meio da realização, ao mesmo tempo, de objetivos sociais, econômicos e ambientais. "Questões sociais, ambientais e econômicas compõem o contexto de desenvolvimento sustentável no qual a sociedade está inserida" (Macêdo \& Martins, 2015, p. 155).

De acordo com Elkington (1994), o objetivo do desenvolvimento sustentável é buscar um equilíbrio entre estas dimensões, definindo como meta ações que sejam ambientalmente responsáveis, socialmente justas e economicamente viáveis, definidas como triple bottom line. No Quadro 1 estão apresentados os indicadores de sustentabilidade da triple bottom line.

QUADRO 1 - INDICADORES DE SUSTENTABILIDADE

\begin{tabular}{|l|l|l|}
\hline \multicolumn{1}{|c|}{ AMBIENTAL } & \multicolumn{1}{c|}{ SOCIAL } & ECONÔMICA \\
\hline Uso do solo & Saúde & Valor agregado \\
\hline Conservação do ambiente & Educação & Vesenvolvimento econômico \\
\hline Uso da água & Segurança & $\begin{array}{l}\text { Custo benefício; custo ao longo da vida útil } \\
\text { da edificação }\end{array}$ \\
\hline Eficiência energética & Acessibilidade & Cultura \\
\hline Poluição & Cestão & \\
\hline Transporte & &
\end{tabular}

OS, Organizações e Sustentabilidade, 8(2), p. 34-53, Londrina, PR, jun./dez. 2020. 
Fonte: Adaptado de "Ferramenta de Avaliação de Sustentabilidade Ambiental em Edificações," R. V. A. Lobo, 2010, p. 58.

Vale enfatizar que as dimensões social e cultural da sustentabilidade estão ligadas a homogeneidade social, onde existe distribuição de renda justa, que promova o acesso igualitário de recursos e serviços sociais, e que haja respeito à tradição e as características locais de cada região. Se tratando do âmbito ambiental, Elkington (1994) coloca em evidência o respeito aos ecossistemas e a substituição do uso de recursos não renováveis pelos renováveis. Na dimensão econômica visa-se um desenvolvimento econômico equilibrado, com inovações tecnológicas em prol do desenvolvimento.

Com o passar dos anos, "a importância do desenvolvimento sustentável ganhou enfoque e destaque mundial, a partir da consciência de que a sociedade não consegue se desenvolver com base apenas nas questões econômicas". Existe a necessidade de que isso ocorra de maneira equilibrada, "considerando que o ambiente natural não receba impactos maiores do que sua capacidade de regeneração" (Macêdo \& Martins, 2015, p. 155).

Contemporaneamente é mais fácil para a sociedade perceber que o desenvolvimento econômico que visa a geração de riqueza e o conforto, vai à contramão das iniciativas necessárias para um desenvolvimento sustentável, no qual este último visa atender essas duas demandas simultaneamente, e é a meta da civilização (Mano, Pacheco \& Bonelli, 2010).

Sachs (2007) enfatiza que a recuperação urbana e a criação de incentivos para a melhoria do meio ambiente urbano deveriam se tornar prioridades nos planos de desenvolvimento dos países, ou seja, a fim de proporcionar melhores condições de vida para a população progredir com 0 desenvolvimento sustentável.

A preocupação da sociedade a respeito do caminho do desenvolvimento sustentável do planeta remete ao início de uma revolução que mudará os conceitos de crescimento inteligente, como afirmam Mihelcic e Zimmerman (2012). Os supracitados autores entendem que a sociedade e a comunidade da engenharia estão no início de uma novíssima revolução, e que os engenheiros podem contribuir significativamente por meio de suas capacidades e potenciais para conceberem e gerenciarem o futuro com projetos inovadores e sustentáveis. Diante do exposto, aborda-se na sequência sobre a relação entre a engenharia civil e o desenvolvimento sustentável.

\section{ENGENHARIA CIVIL E DESENVOLVIMENTO SUSTENTÁVEL}

O crescimento populacional e a urbanização acelerada nas cidades fizeram com que a demanda na construção civil aumentasse nas últimas décadas, gerando grande impacto ambiental, econômico e social. O impacto do crescimento populacional repercute na forma como os recursos naturais são gerenciados e como se projeta e se investe nas obras de engenharia. A construção civil é a principal responsável pelas modificações na paisagem natural, uma vez que é fornecedora de toda a infraestrutura para o desenvolvimento das atividades humanas (CIB, 2000).

A construção é o amplo mecanismo/processo para a localização de assentamentos de pessoas, por meio da criação de infraestrutura que apoia o desenvolvimento. Isso inclui a extração e o beneficiamento de matérias-primas, a fabricação de materiais e componentes de construção, 0 ciclo do projeto de construção, desde a viabilidade até a sua desconstrução, abrangendo o gerenciamento e operação do ambiente construído (Alsubeh, 2013).

Como menciona Motta (2009), os impactos que a construção civil gera, principalmente no ramo de edificações, estão relacionados ao consumo dos recursos naturais do planeta e a geração de resíduos. Isso ocorre não apenas durante a construção do edifício, mas também durante a vida útil do mesmo.

OS, Organizações e Sustentabilidade, 8(2), p. 34-53, Londrina, PR, jun./dez. 2020

ISSN 2318-9223, http://www.uel.br/revistas/uel/index.php/ros/issue/view/1683/showToc 
Cerca de $40 \%$ a $75 \%$ do volume total de recursos naturais que se emprega no setor produtivo é consumido pela construção civil (Mendes, 2013). Ademais, em levantamentos realizados em cidades brasileiras, ficou em evidência que os resíduos da construção civil chegam a representar cerca de 50\% da massa dos resíduos sólidos urbanos (Santos, Cândida \& Ferreira, 2010).

Nesse sentido, conforme a Abrelpe (2014), no ano de 2014 foi coletado nos municípios brasileiros, aproximadamente 45 milhões de toneladas de resíduos da construção e demolição. Isso representa um aumento de 4,1\% em relação a 2013, não refletindo o total dos resíduos gerados. Em geral, os municípios coletam os resíduos de obras "sob sua responsabilidade e os lançados em logradouros públicos" (Abrelpe, 2014, p. 83).

Além dos fatores citados anteriormente, observa-se, com base em Acosta (2009), que a ocupação indiscriminada do espaço, quando há planejamento inadequado das construções, que isso acaba esgotando os recursos, destruindo paisagens e aumentando a sua vulnerabilidade.

Conforme Pinto (1999), também é possivel notar os impactos sonoros, visuais e a poluição do ar (poeira), causados na execução de obras de edificações. Ainda vale lembrar, segundo Acosta (2009), sobre o consumo energético que ocorre durante todo o ciclo de vida das edificações, desde a extração de matéria prima e seu transporte até as obras, passando pelo uso da edificação até as posteriores modificações ou demolições.

Como a construção é considerada uma das principais fontes de poluição ambiental no mundo, o nivel de conhecimento e de conscientização dos participantes do projeto, especialmente dos gerentes de projeto, em relação aos impactos da construção no meio ambiente, precisam ser aprimorados (Irizarry et al., 2012). De maneira geral, o que se busca é uma construção que seja sustentável, que utilize de maneira racional os recursos naturais.

A abordagem de construção sustentável envolve considerar uma forma de a indústria da construção avançar no desenvolvimento sustentável levando em conta questões ambientais, sociais e econômicas. Também é uma maneira de retratar a responsabilidade do setor em proteger o meio ambiente, por meio de práticas de construção que aplicam vários métodos no processo de implementação de projetos de construção (Akadiri, Chinyio \& Olomolaiye, 2012).

Os princípios da construção sustentável aplicam-se ao longo de todo o ciclo de vida da construção, desde o planejamento até a sua eventual desconstrução (Hill \& Bowen, 1997; Kibert, 2008). Tais princípios se aplicam aos recursos necessários para criar e operar o ambiente construído durante todo o seu ciclo de vida: terra, materiais, água, energia e ecossistemas (Kibert, 2008).

Sendo assim, é imperativo para a sociedade atual colocar em prática o conceito de construção sustentável que, na visão do Instituto para o Desenvolvimento da Habitação Ecológica (IDHEA, 2005, p.2), é baseado na criação de um modelo que possa permitir a construção civil "enfrentar e propor soluções aos principais problemas ambientais de nossa época, sem renunciar à moderna tecnologia e à criação de edificações que atendam às necessidades de seus usuários".

Vale dizer que os projetos habitacionais sustentáveis implicariam na melhoria da qualidade de vida dos moradores mediante o uso adequado dos recursos naturais locais, com um projeto que utiliza uma abordagem que respeita o local da obra, o clima, as características culturais e as necessidades humanas (Oktay, 1999 apud Reis \& Lay, 2010).

Para Mihelcic e Zimmerman (2012), o papel do engenheiro no desenvolvimento sustentável é muito importante, pois é de responsabilidade deste realizar o projeto que será executado. É na fase do projeto que se alcança maior influência em termos de sustentabilidade e os engenheiros podem selecionar e avaliar soluções que minimizem os impactos adversos e que maximizem os benefícios para a economia, a sociedade e o meio ambiente. 
Com objetivo de viabilizar construções voltadas para o desenvolvimento sustentável, que provoquem menos danos ao meio ambiente, existem alguns aspectos que podem ser levados em consideração na indústria da construção civil. No entendimento de Salgado (2008), estes aspectos podem ser agrupados conforme está apresentado no Quadro 2.

QUADRO 2 - ASPECTOS DA CONSTRUÇÃO SUSTENTÁVEL

\begin{tabular}{|l|l|lr|}
\hline \multicolumn{1}{|c|}{ SETOR DA CONSTRUÇÃO CIVIL } & \multicolumn{2}{c|}{ PROCESSO DE PROJETO } & \multicolumn{2}{c|}{ PRODUTO EDIFICAÇÃO } \\
\hline Ênfase na formação profissional. & $\begin{array}{l}\text { Reengenharia do processo } \\
\text { construtivo, com maior integração } \\
\text { dos agentes. }\end{array}$ & $\begin{array}{l}\text { Definição de padrões e } \\
\text { melhoria da qualidade } \\
\text { ambiental das construções. }\end{array}$ \\
\hline $\begin{array}{l}\text { Identificação e fortalecimento de } \\
\text { oportunidades de reciclagem de } \\
\text { resíduos de construção e demolição. }\end{array}$ & $\begin{array}{l}\text { Intensificação do caráter } \\
\text { multidisciplinar do projeto. }\end{array}$ & $\begin{array}{l}\text { Adoção de princípios de } \\
\text { projetos ambientalmente } \\
\text { responsáveis. }\end{array}$ \\
\hline $\begin{array}{l}\text { Melhoria da segurança no ambiente de } \\
\text { trabalho. Educação, informação e } \\
\text { sensibilização pública. }\end{array}$ & $\begin{array}{l}\text { Melhoria no gerenciamento do de } \\
\text { processo construtivo. }\end{array}$ & $\begin{array}{l}\text { Desenvolvimento } \\
\text { normas orientadas à } \\
\text { qualidade ambiental de } \\
\text { edifícios. }\end{array}$ \\
\hline
\end{tabular}

Fonte: Elaborado pelos autores, com base em "Projeto integrado - caminho para a produção de edificações sustentáveis: a questão dos sistemas prediais", M. S. Salgado, 2008

Convém notar que a sustentabilidade na construção é alcançada quando há planejamento no setor operante, bem como nas etapas de concepção da edificação até seu produto final, oferecendo maior valor agregado ao produto e atendendo de forma efetiva às partes interessadas (Silva, 2003).

Por conseguinte, a engenharia tem a oportunidade de continuar a se desenvolver, entretanto, com o intuito de melhorar a qualidade de vida ao projetar, desenvolver, implementar e manter uma infraestrutura que não cause tamanha degradação ao meio ambiente, que não tenha consumo excessivo e desperdício de recursos naturais e que não provoque impactos negativos para a sociedade.

\section{Metodologias de AVALIAÇÃo de PRÁticas SUSTENTÁVEIS}

Conforme Reed, Bilos, Wilkinson \& Schulte (2009), foi na década de 90 que surgiram as primeiras metodologias para elaboração de projetos sustentáveis. Essas metodologias são exercidas e administradas por organizações como, por exemplo, o Building Research Establishment Enviromental Assessment Method (BREEAM), exercido no Reino Unido; o Leardership in Energy and Environmental Design $\left(\mathrm{LEED}^{\mathrm{TM}}\right)$, estabelecido pelo United States Green Building Council USGBC.

Jagger (2011, p. 2) cita que o primeiro método proposto foi o inglês BREEAM, na década de 90. "Este selo define o padrão das melhores práticas em design sustentável" a partir da atribuição de créditos, em dez categorias, conforme o desempenho alcançado pela proposta. A maioria dos requisitos pode ser negociada, ou seja, a equipe do projeto pode escolher quais requisitos vão atender para atingir a pontuação necessária (BRE Global Ltd, 2010).

0 método de avaliação norte-americano LEED ${ }^{\text {TM }}$ surgiu no ano de 2000, e tem como objetivos melhorar o bem-estar dos ocupantes, aumentar o desempenho ambiental e o retorno econômico dos edifícios, bem como adotar práticas estabelecidas e inovadoras. Para obter a certificação LEED $^{\text {TM }}$ o projeto-candidato deve satisfazer a todos os pré-requisitos e obter um número mínimo de pontos nos requisitos, de forma a atingir os índices propostos (Salgado \& Lemos, 2005).

Posteriormente, no ano de 2002, surgiu o método francês Haute Qualité Environmentale (HQE ${ }^{\circledR}$ Alta Qualidade Ambiental, devido à preocupação com o desempenho energético das edificações, empresas e profissionais da área repensaram seu processo de projeto e construção. A metodologia

OS, Organizações e Sustentabilidade, 8(2), p. 34-53, Londrina, PR, jun./dez. 2020. 
$\mathrm{HQE}^{\circledR}$ é uma das que vêm sendo utilizada na realização dos projetos das edificações na França, sendo uma exigência nas concorrências públicas (Salgado, Chatelet \& Fernandez, 2012).

O primeiro sistema brasileiro de certificação ambiental de edifícios para o setor da construção civil foi estabelecido em 2007. Trata-se do "Referencial Técnico de Certificação: Edifícios do setor de serviços, sistema Alta Qualidade Ambiental (AQUA)", que tem como base o método francês HQE ${ }^{\circledR}$. É importante dizer que sistema AQUA foi adequado para a realidade brasileira pela Fundação Vanzolini (Aulicino, 2008).

Em 2010, a Caixa Econômica Federal apresentou uma proposta para estimular a construção sustentável no Brasil - o Selo Azul, que consiste na verificação feita pela análise de viabilidade técnica conforme o atendimento aos 53 critérios de avaliação distribuídos em categorias que orientam a classificação do projeto (John, 2010).

Bauer, Schwarz e Mösle (2010) citam que as metodologias de classificação foram desenvolvidas para medir o nivel de sustentabilidade das edificações e fornecer a experiência de melhores práticas em seu mais alto nivel de certificação. Os critérios abrangem saúde humana e ambiental, eficiência energética, economia de água, seleção de materiais, qualidade ambiental interna, desenvolvimento sustentável dos locais da edificação, aspectos sociais e qualidade econômica.

No Quadro 3 é possivel verificar uma breve relação das categorias abordadas pelos métodos de certificações, Selo Azul da Caixa; LEED ${ }^{\mathrm{T}}$; AQUA e o BREEAM.

QUADRO 3 - COMPARATIVO ENTRE OS MÉTODOS DE CERTIFICAÇÕES

\begin{tabular}{|l|l|l|l|l|}
\hline \multicolumn{1}{|c|}{ CATEGORIAS } & SELO AZUL & \multicolumn{1}{c|}{ LEED $^{\text {TM }}$} & \multicolumn{1}{c|}{ AQUA } & \multicolumn{1}{c|}{ BREEAM $^{-1}$} \\
\hline Saúde e Conforto & $\mathrm{X}$ & $\mathrm{X}$ & $\mathrm{X}$ & $\mathrm{X}$ \\
\hline Eficiência Energética & $\mathrm{X}$ & $\mathrm{X}$ & $\mathrm{X}$ & $\mathrm{X}$ \\
\hline Uso da água & $\mathrm{X}$ & $\mathrm{X}$ & $\mathrm{X}$ & $\mathrm{X}$ \\
\hline Uso do Solo & $\mathrm{X}$ & $\mathrm{X}$ & $\mathrm{X}$ & $\mathrm{X}$ \\
\hline Uso de materiais & $\mathrm{X}$ & $\mathrm{X}$ & $\mathrm{X}$ & $\mathrm{X}$ \\
\hline Qualidade urbana & $\mathrm{X}$ & $\mathrm{X}$ & $\mathrm{X}$ & $\mathrm{X}$ \\
\hline Poluição & $\mathrm{X}$ & $\mathrm{X}$ & $\mathrm{X}$ & $\mathrm{X}$ \\
\hline Práticas Sociais & $\mathrm{X}$ & & & \\
\hline
\end{tabular}

Fonte: Elaborado pelos autores.

É possível perceber, no Quadro 3, que os métodos citados são construídos sobre uma base comum. Porém, de acordo com Silva (2003), eles são bastante diferentes. O autor comenta que as diferenças principais estão ligadas aos niveis de pressão sobre determinados aspectos ambientais que variam de um país para o outro, porque as práticas construtivas e de projeto são diferentes e também influenciadas - porém não somente - por aspectos climáticos. Por último, cita que a receptividade dos mercados à introdução dos métodos é diferente em cada país.

As iniciativas de mensurar o nível de sustentabilidade da edificação visam esclarecer critérios e parâmetros objetivos do desempenho de edificações, trazendo tacitamente inclusa a busca de um desenvolvimento sustentável (Silva, 2003). O propósito dos sistemas de classificação é certificar os diferentes aspectos durante a vida útil da edificação (Bauer, Schwarz \& Mösle, 2010). Para Borges e Sabatini (2008), a preocupação com o desempenho das edificações se tornou uma tendência mundial, em contrapartida, o Brasil ainda possui um longo caminho a percorrer, pois toda a normalização técnica brasileira existente referente à construção civil, por exemplo, é prescritiva e tem a preocupação quanto à maneira que o produto deve ser construído, e não com o desempenho esperado do mesmo.

Como no Brasil apenas foram dados os primeiros passos rumo à preocupação com o desenvolvimento sustentável, e tendo em vista que, anteriormente à criação do Selo de Qualidade Azul da Caixa e do selo AQUA, os métodos utilizados para a certificação de edifícios no Brasil eram provenientes de outros países, como França, Reino Unido e Estados Unidos, para este trabalho 
optou-se por utilizar como ferramenta de análise das práticas de sustentabilidade os selos: Azul da Caixa; LEED ${ }^{\mathrm{TM}}$; AQUA e BREEAM.

Desde modo, as práticas de sustentabilidade utilizadas na construção civil consideradas aplicáveis para este trabalho contemplam as categorias: saúde e conforto; eficiência energética; uso da água; uso de materiais; uso do solo; qualidade urbana; poluição; práticas sociais, e seus respectivos aspectos, apresentadas no Quadro 4, no qual foi elaborado com base em: Manual Selo Azul da Caixa (John \& Prado, 2010), FCAV e CERQUAL (2013), U.S. Green Building Council (2009) e BRE Global Ltd (2011).

QUADRO 4 - CATEGORIAS E ASPECTOS REFERENTES ÀS PRÁTICAS DE SUSTENTABILIDADE UTILIZADAS NA CONSTRUÇÃO CIVIL

\section{Categorias Aspectos}

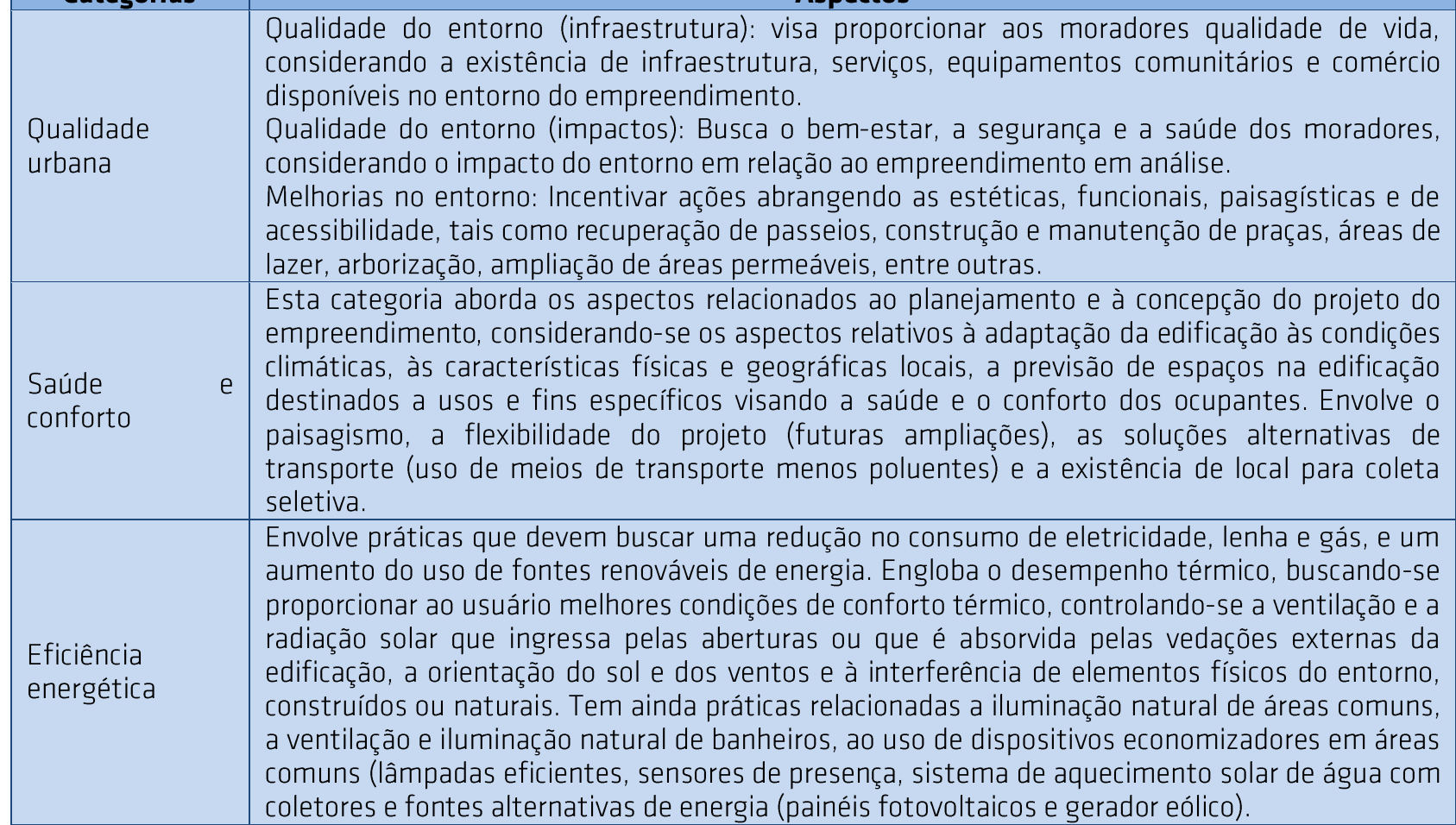

A construção depende de um fluxo constante de materiais, da atividade de limpeza do terreno, passando pelas atividades de construção, manutenção, e evitáveis operações de correção de patologias, até o fim da vida útil do edifício ou de suas partes, onde fluxos importantes de resíduo serão gerados. É preciso reduzir as perdas de materiais pela necessidade de cortes, ajustes de componentes e uso de material de enchimento (coordenação modular); evitar o uso

Uso de materiais produtos de baixa qualidade. Também deve-se reduzir o consumo de recursos naturais (utilizados na correção) e as perdas de materiais e a geração de resíduos (por meio do emprego de componentes industrializados montados em canteiro, tais como: divisórias internas, lajes, vigas, pilares, entre outros). É importante a utilização de materiais reutilizáveis, tais como os agregados reciclados no projeto de pavimento, bem como de madeira plantada ou certificada. Deve-se adotar o uso de fôrmas e escoras reutilizáveis, reduzindo o emprego de madeira em aplicações de baixa durabilidade, no qual proporciona evitar o desperdício de materiais.

Trata-se da adequação às condições físicas do terreno. Envolve verificar o grau de movimentação Uso do solo de terra para a implantação do empreendimento. A implantação deve tirar proveito das declividades e de elementos naturais do terreno, como rochas, corpos hídricos, vegetação, com a minimização de cortes, aterros e contenções.

A gestão da água em edifícios é indispensável para um uso mais sustentável deste insumo, pois contribui para mitigar os problemas de escassez, amenizar a poluição em águas superficiais e profundas e, ainda, reduzir os riscos de inundação em centros urbanos. Envolve a existência de Uso daágua sistema de medição individualizada de água e os dispositivos economizadores em bacia sanitária, em registro regulador de vazão no chuveiro, em torneiras de lavatório e na pia. Deve priorizar o aproveitamento de águas pluviais (para usos em: bacia sanitária, irrigação de áreas verdes, lavagem de pisos, lavagem de veículos) e a infiltração de águas pluviais, permitindo 0

OS, Organizações e Sustentabilidade, 8(2), p. 34-53, Londrina, PR, jun./dez. 2020.

ISSN 2318-9223, http://www.uel.br/revistas/uel/index.php/ros/issue/view/1683/showToc 


\begin{tabular}{|l|l|}
\hline \multirow{3}{*}{ Poluição } & $\begin{array}{l}\text { seu escoamento de modo controlado ou favorecer a sua infiltração no solo, visando prevenir o } \\
\text { risco de inundações. Também deve ter a existência de áreas permeáveis em, pelo menos, 10\% } \\
\text { acima do exigido pela legislação local. }\end{array}$ \\
\hline Práticas sociais & $\begin{array}{l}\text { Trata-se da gestão de residuos de construção e demolição: Envolve reduzir a quantidade de } \\
\text { resíduos de construção e demolição e seus impactos no meio ambiente urbano, com um “Projeto } \\
\text { de Gerenciamento de Resíduos da Construção Civil (PGRCC)" para a obra. Contempla a } \\
\text { apresentação, ao final da respectiva obra, dos documentos de comprovação de destinação e } \\
\text { disposição final ambientalmente adequada dos resíduos gerados. }\end{array}$ \\
\hline $\begin{array}{l}\text { Inclusão de trabalhadores locais: Visa promover a ampliação da capacidade econômica dos } \\
\text { moradores da área de intervenção e seu entorno ou de futuros moradores do empreendimento } \\
\text { por meio da contratação deles, estabelecendo uma relação positiva dos mesmos com o } \\
\text { empreendimento. Participação da comunidade na elaboração do projeto, com a participação e o } \\
\text { envolvimento desta na implementação do empreendimento. }\end{array}$ \\
\hline
\end{tabular}

Convém dizer que cada um destes aspectos básicos, referentes às práticas de sustentabilidades utilizadas na construção civil, podem ser ampliados tendo como base as suas respectivas categorias e sem prejuízo a estas.

\section{PROCEDIMENTOS METODOLÓGICOS}

Com vistas a facilitar a compreensão dos procedimentos metodológicos, o processo de pesquisa deste estudo está baseado na abordagem de Saunders, Lewis e Thornhill (2003), como apresentado na Figura 1.

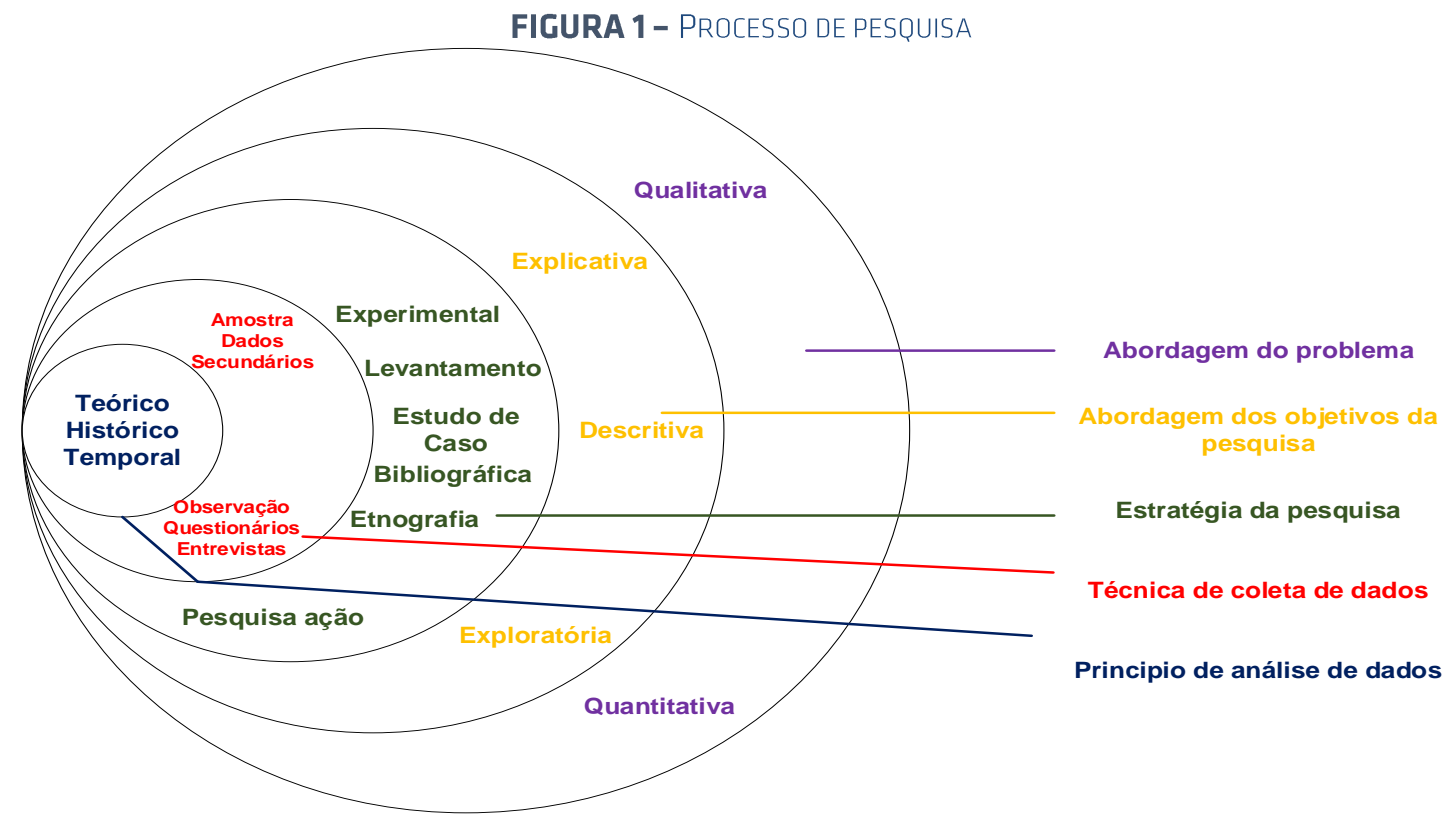

Fonte: Adaptado pelos autores, com base em "Research Methods for business sutendents", M. Saunders, P. Lewis, \& A. Thornhill, 2003.

A presente pesquisa se caracteriza como sendo quantitativa (abordagem do problema); do tipo descritiva (abordagem dos objetivos da pesquisa); com levantamento de dados em empresas construtoras de edificações (estratégia de pesquisa), sendo dividida em duas etapas: pesquisa em fontes secundárias e estudo do tipo survey.

A análise da sustentabilidade em empresas da construção civil depende da revisão das práticas de sustentabilidade que podem ser adotadas pelo setor da construção civil. Em vista disso, primeiramente realizou-se uma revisão bibliográfica, onde foi possível verificar:

OS, Organizações e Sustentabilidade, 8(2), p. 34-53, Londrina, PR, jun./dez. 2020

ISSN 2318-9223, http://www.uel.br/revistas/uel/index.php/ros/issue/view/1683/showToc 
- o entendimento de desenvolvimento sustentável, de sustentabilidade, como também o reconhecimento dos indicadores de sustentabilidade em cada dimensão;

- a relação entre a engenharia civil e o desenvolvimento sustentável, como o setor influencia neste desenvolvimento e a importância do papel do engenheiro civil na elaboração de projetos que sigam os princípios de uma edificação sustentável;

- o conhecimento dos principais métodos de certificação ambiental utilizados para a certificação de edifícios quanto à sustentabilidade e as práticas sustentáveis que os mesmos levam em consideração;

- o conhecimento das práticas consideradas sustentáveis na construção civil, com base nos requisitos para obtenção dos selos de qualidade mencionados neste trabalho (LEED ${ }^{T M}$, BREEAM, ÁQUA e Selo Azul da Caixa).

A partir do conhecimento das práticas de sustentabilidade, e na busca dos objetivos pretendidos neste trabalho, realizou-se uma pesquisa de campo junto às empresas do setor da construção civil, buscando-se identificar quais práticas de sustentabilidade que as mesmas vêm adotando em suas edificações.

Fizeram parte deste estudo seis empresas do setor de edificações da construção civil, localizadas no Sul do Brasil, conforme está apresentado no Quadro 5, onde optou-se por uma amostra não probabilística. Cabe dizer que este tipo de amostragem pode ser usado em casos onde a população de trabalho não pode ser enumerada (número de empresas que aplicam práticas sustentáveis na construção de edificações), sendo particularmente importante quando é difícil identificar respondentes em potencial.

Nesta amostragem intencional (empresas que estão localizadas no Sul do Brasil) o pesquisador deliberadamente escolhe alguns elementos para fazer parte da amostra, portanto, os resultados da amostra não foram estatisticamente generalizados para a população. Cabe citar que a escolha destas empresas ocorreu em função de acessibilidade e da oportunidade em pesquisá-las.

\begin{tabular}{|l|l|l|l|}
\multicolumn{5}{|c|}{ QUADRO 5 - CARACTERISTICAS DAS EMPRESAS EM ESTUDO } \\
\hline Empresa & \multicolumn{1}{|c|}{ Localização } & \multicolumn{1}{c|}{ Porte } & \multicolumn{1}{c|}{ Área de atuação } \\
\hline A & Horizontina - RS & $\begin{array}{l}\text { Pequen } \\
0\end{array}$ & $\begin{array}{l}\text { Projetos de edificações comerciais e unifamiliares de pequeno porte e } \\
\text { acompanhamento de obras. }\end{array}$ \\
\hline B & Alegrete - RS & Médio & Projeto e execução de obras em geral. \\
\hline C & Caxias do Sul - RS & Grande & Projeto e execução de obras em geral. \\
\hline D & Caxias do Sul - RS & Médio & Projeto e execução de obras em geral. \\
\hline E & Porto Alegre - RS & Grande & Projeto e execução de obras em geral. \\
\hline F & Curitiba- PR & Grande & Projeto e execução de obras em geral. \\
\hline
\end{tabular}

Para a coleta de dados (técnica de coleta de dados) nestas organizações utilizou-se de questionário com questões fechadas, no qual foi elaborado a partir do estudo das práticas de sustentabilidade exigidas pelos selos de qualidade ambiental, sendo aplicado in loco ao responsável técnico pela área de gerenciamento de projetos e execução de obras de cada uma delas, ocorrendo no final do ano de 2015 e início de 2016. Para preservar o anonimato das empresas participantes deste estudo, optou-se em denominá-las de empresa A; B; C; D; E; F.

Posteriormente à obtenção destes dados, procedeu-se à sua organização e análise teórica (princípios de análise de dados), considerado as características da pesquisa e do objetivo estabelecido. Assim, como técnica de coleta de dados foi aplicado um questionário e como princípio de análise de dados utilizou-se a análise teórica, confrontando-se os dados obtidos com o referencial teórico sobre o tema da pesquisa.

OS, Organizações e Sustentabilidade, 8(2), p. 34-53, Londrina, PR, jun./dez. 2020. 


\section{APRESENTAÇÃO E ANÁLISE DOS RESULTADOS}

Os resultados deste estudo são mostrados e analisados de maneira a verificar se as práticas adotadas por seis empresas (caracterizadas como A; B; C; D; E; F) que atuam na construção de edifícios sustentáveis estão em conformidade com os três elementos que compõem o pilar do desenvolvimento sustentável, tendo como base de pesquisa as categorias de qualidade urbana; de saúde e conforto ligado aos benefícios que as edificações oferecem aos seus moradores; de eficiência energética; conservação de recursos naturais; de uso do solo; de gestão da água; de controle da poluição e de aplicação de práticas sociais; conforme está apresentado no Quadro 6.

QUADRO 6 - PRÁTICAS SUSTENTÁVEIS ADOTADAS PELAS EMPRESAS

\begin{tabular}{|c|c|c|c|}
\hline CATEGORIA / PRÁTICAS & UTILIZA & $\begin{array}{l}\text { RARAMENTE } \\
\text { UTILIZA }\end{array}$ & NÃO UTILIZA \\
\hline \multicolumn{4}{|l|}{ Qualidade urbana } \\
\hline Qualidade do entorno (infraestrutura) & C; D;E; F & $\mathrm{B}$ & A \\
\hline Qualidade do entorno (impactos) & $\mathrm{E}$ & $C ; D ; F$ & $A ; B$ \\
\hline Melhoria no entorno & $C ; E ; F$ & $\mathrm{D}$ & $A ; B$ \\
\hline \multicolumn{4}{|l|}{ Saúde e conforto } \\
\hline Paisagismo & C; D;E; F & $A ; B$ & \\
\hline Flexibilidade de projeto & B & $C ; E ; F$ & $A ; D$ \\
\hline Local para coleta seletiva & $\mathrm{F}$ & $A ; B ; C ; D ; E$ & \\
\hline Solução alternativa de transporte & $\mathrm{F}$ & B; C; D; E & A \\
\hline \multicolumn{4}{|l|}{ Eficiência energética } \\
\hline Desempenho térmico & $B ; C ; D ; E ; F$ & & A \\
\hline lluminação natural de áreas comuns & Todas & & \\
\hline Ventilação e iluminação natural de banheiros & Todas & & \\
\hline Dispositivos economizadores & & $B ; C ; E ; F$ & $A ; D$ \\
\hline Sistema de aquecimento solar de água com coletores & & Todas & \\
\hline Fontes alternativas de energia & $\mathrm{F}$ & & $A ; B ; C ; D ; E$ \\
\hline \multicolumn{4}{|l|}{$\begin{array}{l}\text { Recursos naturais } \\
\end{array}$} \\
\hline Coordenação modular & $\mathrm{B} ; \mathrm{E}$ & & $A ; C ; D ; F$ \\
\hline Qualidade de materiais e componentes & C; D;E; F & $A ; B$ & \\
\hline Componentes pré-fabricados & C; D;E; F & $\mathrm{B}$ & A \\
\hline Fôrmas e escoras reutilizáveis & & $B ; C ; E ; F$ & $A ; D$ \\
\hline Pavimentação com agregados reciclados & $\mathrm{E}$ & $A ; B ; C ; F$ & $\mathrm{D}$ \\
\hline Madeira plantada ou certificada & & $E ; F$ & $A ; B ; C ; D$ \\
\hline \multicolumn{4}{|l|}{ Uso do Solo } \\
\hline Adequação às condições físicas do terreno & & C; D;E; F & $A ; B$ \\
\hline \multicolumn{4}{|l|}{ Cestão da água } \\
\hline Medição individualizada & Todas & & \\
\hline Dispositivos economizadores (bacia sanitária) & & $D ; E ; F$ & $A ; B ; C$ \\
\hline $\begin{array}{l}\text { Dispositivo economizadores (registro regulador de } \\
\text { vazão) }\end{array}$ & & $D ; E ; F$ & $A ; B ; C$ \\
\hline Aproveitamento de águas pluviais & & $E ; F$ & $A ; B ; C ; D$ \\
\hline Infiltração de águas pluviais & & $A ; B$ & C; D;E; F \\
\hline Áreas permeáveis & & $C ; D$ & $\mathrm{~A} ; \mathrm{B} ; \mathrm{E} ; \mathrm{F}$ \\
\hline \multicolumn{4}{|l|}{ Poluição } \\
\hline Gestão de resíduos de construção e demolição & C; D;E; F & B & A \\
\hline \multicolumn{4}{|l|}{ Práticas sociais } \\
\hline Inclusão de trabalhadores locais & & $B ; C ; E$ & $A ; D ; F$ \\
\hline Participação da comunidade na elaboração do projeto & & & Todas \\
\hline
\end{tabular}

$$
\text { Fonte: Elaborado pelos autores. }
$$

Em relação à categoria qualidade urbana, verifica-se que a maioria das empresas $(C ; D ; E ; F)$ adotam as práticas referentes à qualidade do entorno, sendo, nesse sentido, aquela que faz referência à infraestrutura, ou seja, a inserção do empreendimento em local que seja dotado de 
infraestrutura básica, como: rede de abastecimento de água potável, pavimentação, energia elétrica, iluminação pública, esgotamento sanitário com tratamento e uma linha de transporte público regular.

Pelos resultados da pesquisa também foi possível observar que a melhoria no entorno também foi citada como aplicada por três empresas (C; E; F), ou seja, metade das participantes do estudo. É preciso atentar, com base em Macêdo \& Martins (2015), que a construção civil, como um agente atuante de forma ativa nos espaços urbanos, é propulsora de impactos que podem interferir na qualidade das cidades. Nesse sentido, a sustentabilidade urbana envolve aspectos presentes nas cidades, nos quais as condições desses espaços devem ocorrer a partir da busca pelo equilíbrio entre o espaço natural e o espaço construído e suas diversas relações de interdependência.

Pelos dados da pesquisa pode-se observar que a categoria qualidade urbana está de acordo com o que preconiza Sachs (2007), no qual pode-se perceber que as empresas estão buscando promover a melhoria do meio ambiente urbano, ao proporcionar melhores condições de qualidade de vida para os moradores.

No que se refere à saúde e conforto, esta categoria está ligada aos benefícios que a edificação oferece aos moradores como: paisagismo, flexibilidade de projeto, ou seja, a possibilidade de modificações ou ampliações, existência de transporte alternativo próximo a edificação e coleta seletiva. A maioria das empresas pesquisadas ( $C ; D ; E ; F)$ aplica a prática de paisagismo em seus empreendimentos.

Na supracitada categoria há a necessidade de que sejam levadas em consideração as práticas relacionadas ao planejamento, à concepção do projeto do empreendimento e o produto final, considerando-se a flexibilidade de projeto, a destinação de um local para coleta seletiva e as soluções alternativas de transporte, visando a saúde e o conforto dos ocupantes, visto que raramente essas práticas são utilizadas pela maioria das empresas. Cabe frisar que, para que as construções sejam realmente sustentáveis, elas devem abranger o processo do projeto e os produtos de edificação, como cita Salgado (2008).

Quanto à eficiência energética, essa categoria está relacionada com práticas que visam buscar a redução no consumo de eletricidade e de gás, e o aumento do uso de fontes renováveis de energia, de maneira que possa proporcionar melhorias no desempenho térmico do edifício, buscando-se propiciar ao usuário melhores condições de conforto térmico. Como destaque nesta prática, observa-se que todas as empresas pesquisadas aplicam soluções referentes a iluminação natural de áreas comuns e a ventilação e iluminação natural de banheiros. Já a maioria das empresas (B; C; D; E; F) aplica a prática de desempenho térmico das edificações - conforto térmico.

Quanto à utilização de dispositivos economizadores e sistema de aquecimento solar, a maioria raramente utiliza essas práticas. Já, quanto as fontes alternativas de energia, estas não são utilizadas pela maioria ( $A ; B ; C ; D ; E)$, sendo que somente uma empresa utiliza tal prática (F). É importante dizer que isso não está em conformidade com o que preconiza Elkington (1994), no que se refere a dimensão ambiental dos três pilares da sustentabilidade, na qual o autor entende que é importante a substituição do uso de recursos naturais não renováveis pelos renováveis.

As práticas referentes à categoria recursos naturais levam em consideração de que o setor da construção civil é um potencial consumidor de recursos e gerador de resíduos. Diante disso, as soluções apresentadas visam à redução dos desperdícios nas atividades relacionadas à construção civil, bem como a conservação dos recursos naturais. Sendo assim, foi possivel observar que maioria das empresas ( $C ; D ; E ; F$ ) estão aplicando soluções no que se diz respeito a qualidade de materiais e componentes e aos componentes pré-fabricados.

Conforme Elkington (1994), é preciso ter como meta ações que sejam ambientalmente responsáveis, e isso inclui a utilização de recursos não renováveis, ao invés dos renováveis. Nesse

OS, Organizações e Sustentabilidade, 8(2), p. 34-53, Londrina, PR, jun./dez. 2020.

ISSN 2318-9223, http://www.uel.br/revistas/uel/index.php/ros/issue/view/1683/showToc 
sentido, observou-se que raramente as empresas utilizam fôrmas e escoras reutilizáveis ( $B$; $C$; $E$; F), assim como a pavimentação com resíduos de construção e demolição ( $A ; B ; C ; F)$. Ademais, a maioria das empresas ( $A ; C ; D ; F)$ não aplica a técnica de coordenação modular e nem utiliza ( $A$; $B$; C; D) a madeira de plantios florestais plantada ou certificada.

A categoria referente ao uso do solo trata da adequação da obra às condições físicas do terreno, ou seja, de aproveitar as declividades e os elementos naturais do terreno, como as rochas, corpos hídricos, vegetação com a minimização de cortes, aterros e contenções. É possivel notar que a maioria das empresas ( $C ; D ; E ; F)$ raramente utiliza essa prática, e que duas empresas demonstraram não a utilizar. Nesse sentido, é preciso atentar para a afirmação de Acosta (2009), na qual o autor entende que quando não há planejamento adequado, isso pode acabar esgotando os recursos naturais, com a destruição das paisagens, aumentando a sua vulnerabilidade.

A categoria que engloba a gestão da água, por sua vez, se relaciona com ações referentes à economia e ao reaproveitamento da água. Nesse contexto, todas as empresas brasileiras pesquisadas utilizam somente a prática relacionada à medição individualizada em seus edifícios construídos. No que diz respeito às práticas de utilização de dispositivos economizadores (bacia sanitária e registro regulador de vazão) observa-se que metade das empresas não utiliza essas soluções e que a outra metade raramente utiliza. Também foi possivel constatar que, quanto ao aproveitamento de águas pluviais, a infiltração de águas pluviais e as áreas permeáveis, que essas são práticas não utilizadas (maioria das respostas), ou raramente são aplicadas nas empresas pesquisadas.

Os resultados apresentados nas categorias uso do solo e gestão da água demonstram que a engenharia ainda tem oportunidades de melhorias a serem implementadas, na qual é preciso, cada vez mais, projetar, desenvolver, implementar e manter uma infraestrutura que não cause tantos impactos negativos para a sociedade e tanta degradação do meio ambiente, com o consumo excessivo e com o desperdício de recursos naturais. Como diz Salgado (2008), a construção sustentável deve adotar princípios de projetos ambientalmente responsáveis.

Em relação a categoria poluição, verificou-se que ela está diretamente relacionada com a existência de um plano de gerenciamento de resíduos de construção e demolição, ou seja, dar a destinação e a disposição final ambientalmente adequada aos resíduos. Com base em Stumpf, Theis \& Schreiber (2018), entende-se que a geração de resíduos sólidos se apresenta como um aspecto indissociável do processo industrial, o que demanda investimentos e tecnologias para a sua destinação final ambientalmente adequada.

No contexto supracitado, as empresas participantes desta pesquisa, em sua maioria (C; D; E; F), indicaram que utilizam a gestão de resíduos de construção e de demolição, sendo que apenas uma das empresas pesquisadas (A) apontou não fazer uso dessa prática em suas obras. Isso permite confirmar que as empresas estão colocando em prática ações de reciclagem de resíduos de construção e demolição, sendo isso, como afirma Salgado (2008), um aspecto que caracteriza a construção sustentável.

Cabe destacar aqui que foi informado, anteriormente, no que se refere à prática de pavimentação com agregados reciclados, que as empresas ( $A$; B; C; F) raramente adotam tal prática. Fica assim a dúvida se esse gerenciamento de resíduos está levando em consideração a destinação e a disposição final ambientalmente adequada dos resíduos gerados, conforme preconiza a Política Nacional dos Resíduos Sólidos (Brasil, 2010).

A categoria das práticas sociais se refere àquelas práticas que envolvem a população-alvo do empreendimento como, por exemplo, a inclusão de trabalhadores locais na execução das obras e a participação da comunidade nas discussões sobre o projeto. Nota-se que metade das empresas demonstrou raramente incluir trabalhadores locais em suas obras e que a outra metade não utiliza

OS, Organizações e Sustentabilidade, 8(2), p. 34-53, Londrina, PR, jun./dez. 2020.

ISSN 2318-9223, http://www.uel.br/revistas/uel/index.php/ros/issue/view/1683/showToc 
essa prática. Como bem enfatizado por Alsubeh (2013), a construção sustentável é um dos principais assuntos que refletem a degradação ambiental que o mundo enfrenta, e esse problema precisa ser tratado de maneira social e ecologicamente responsável.

lá quanto a participação da comunidade nas discussões de elaboração dos projetos, foi possível verificar na pesquisa que essa prática não é utilizada por nenhuma empresa. Com base em Irizarry et al. (2012), é importante lembrar que o nivel de conhecimento e conscientização dos participantes do projeto, em relação aos impactos da construção no meio ambiente, precisam ser aprimorados. Há uma grande urgência em fazer intervenções sustentáveis agora, enquanto esses ambientes estão sendo construídos, ao invés de tentar mudar após o empreendimento executado (Alsubeh, 2013).

Os projetos devem proporcionar melhorias na qualidade de vida dos moradores, respeitando às características físicas e geográficas locais, às condições climáticas e as necessidades humanas, durante a vida útil da edificação. Isso perpassa pela existência de um plano que contenha ações voltadas para a promover o envolvimento dos futuros moradores do empreendimento, que demonstrem a participação da população-alvo nas discussões e tomadas de decisão na elaboração do projeto, pois eles são os beneficiários diretos do empreendimento.

Os resultados da pesquisa realizada nas empresas que estão localizadas no Sul do Brasil permitem dizer que as empresas C; D; E; F apresentaram melhores resultados quanto a adoção de práticas sustentáveis. Já as empresas A; B não se mostraram favoráveis a adoção de tais práticas. Apesar de tais resultados, pode-se assim dizer, que ainda existe a necessidade de se buscar um equilíbrio entre os três elementos do pilar de sustentabilidade, pois na dimensão social da sustentabilidade não se está promovendo o acesso igualitário de recursos e serviços sociais, sendo necessário definir como meta algumas ações que sejam socialmente justas e economicamente viáveis.

Também é importante correlacionar os resultados da presente pesquisa com as conclusões do estudo realizado por Atombo, Dzantor e Agbo (2015), onde os supracitados autores enfatizaram que o desafio que a indústria da construção está enfrentando não é apenas executar projetos dentro do prazo, custo e qualidade, mas sim integrar vários aspectos no ato de construir, tais como as necessidades econômicas, ambientais e sociais.

\section{CONSIDERAÇÕES FINAIS}

No Brasil, o interesse das empresas do setor da construção civil em aplicar práticas sustentáveis em seus empreendimentos tem aumentado. Vale dizer que este setor está inserido em um cenário cuja preocupação com meio ambiente é vital, seja por ser considerado uma das principais fontes de poluição ambiental no mundo, seja pela imagem da empresa ou seja pelo cumprimento rigoroso de algumas leis ambientais. Diante disso, foi realizada uma análise referente a aplicação de práticas sustentáveis em empresas construtoras de edificações.

Com base nos resultados expostos neste trabalho, pode-se dizer que as empresas pesquisadas estão inserindo em suas obras algumas práticas sustentáveis, tais como as referentes as categorias de qualidade urbana e de saúde e conforto, onde se constataram melhorias na qualidade do entorno (infraestrutura), no entorno (impactos) e no paisagismo. Descobriu-se que a iluminação natural de áreas comuns, ventilação, iluminação natural de banheiros e desempenho térmico das edificações (conforto térmico) são soluções referentes a categoria de eficiência energética que são aplicadas por todas as empresas brasileiras estudadas.

No quesito conservação dos recursos naturais, as empresas estão aplicando soluções relacionadas com componentes pré-fabricados e também com a qualidade de materiais e componentes de suas obras. Na categoria gestão da água, apenas a prática de medição individualizada é aplicada por todas as empresas. Quanto a utilização de dispositivos economizadores, ou esta prática não é

OS, Organizações e Sustentabilidade, 8(2), p. 34-53, Londrina, PR, jun./dez. 2020. 
empregada nas edificações ou ela é raramente utilizada pelas empresas. Já a categoria de poluição, na qual se refere à gestão de resíduos de construção e demolição, observa-se que a mesma é aplicada pela maioria das empresas.

Ficou evidente que existe exigências do mercado e que as empresas construtoras de edificações estão aos poucos se readequando com a aplicação de algumas práticas sustentáveis. No entanto, entende-se que nas empresas pesquisadas ainda não há o equilíbrio entre as três dimensões da sustentabilidade. Ainda existe espaço para serem implementadas melhorias, pois outras medidas poderiam ser adotadas pelas empresas, tais como promover o uso de fontes alternativas de energia (categoria de eficiência energética), de dispositivos economizadores (categoria gestão da água), de usar trabalhadores locais e de ter a participação da comunidade na elaboração do projeto (categoria práticas sociais), bem como de adequar a obra às condições físicas do terreno (categoria uso do solo) e de utilizar madeira plantada ou certificada (categoria recursos naturais).

Diante os resultados obtidos, concluiu-se que para a amostra pesquisada o modo de produção adotado ainda não está totalmente de acordo com o que se denomina desenvolvimento sustentável, apesar de ter sido constatada a adoção de algumas práticas sustentáveis nos projetos executados pelas empresas construtoras de edificações participantes desta pesquisa. Conforme citado no referencial teórico utilizado neste estudo, entende-se que, para que realmente ocorra 0 desenvolvimento sustentável, as principais medidas adotadas no empreendimento de novas edificações necessitam abranger, de forma equilibrada, os três elementos do pilar de sustentabilidade, executando-se ações que sejam ambientalmente responsáveis, socialmente justas e economicamente viáveis.

Acredita-se que o estudo proporcionou importantes análises para a compreensão das práticas adotadas por algumas empresas brasileiras na construção de edifícios sustentáveis. Entretanto, devido ao estudo contemplar uma amostra não probabilística, os resultados não podem ser estatisticamente generalizados para a população, ficando assim evidente a necessidade ampliação do estudo, desenvolvendo-o em uma amostra representativa de empresas construtoras de edificações.

\section{REFERÊNCIAS}

Abrelpe. (2014). Panorama dos Resíduos Sólidos no Brasil 2014. Recuperado de www.abrelpe.org.br/Panorama/panorama2014.pdf

Acosta, D. (2009). Arquitectura y construcción sostenibles: conceptos, problemas y estrategias. DEARQ - Revista de Arquitectura / Journal of Architecture, 4, p. 14-23. Recuperado de http://www.redalyc.org/articulo.oa?id=341630313002. ISSN 2011-3188

Akadiri, P. O., Chinyio, E. A., \& Olomolaiye, P. O. (2012). Design of A Sustainable Building: A Conceptual Framework for Implementing Sustainability in the Building Sector. Buildings, 2(2), p. 126-152. Recuperado de http://www.mdpi.com/2075-5309/2/2/126. doi.org/10.3390/buildings2020126

Alsubeh, M. A. (2013). A strategic framework for sustainable construction in Jordan. Civil and Environmental Research, 3(2), p.102-108. Recuperado de http://www.iiste.org/Journals/index.php/CER/article/view/4236. ISBN 2222-2863 (online)

Atombo, C., Dzantor, J. C. K., \& Agbo, A. A. (2015). Integration of Sustainable Construction in Project Management: A Case Study in Ghana. International Journal of Construction Engineering and $\begin{array}{llll}\text { Management, } & 4(1), & \text { p. } & \text { Recuperado } 25 .\end{array}$ http://article.sapub.org/10.5923.j.ijcem.20150401.02.html. doi:10.5923/j.ijcem.20150401.02 
Aulicino P. (2008). Análise de Métodos de Avaliação de Sustentabilidade do Ambiente Construído: o caso dos conjuntos habitacionais. (Dissertação de Mestrado). Escola Politécnica da Universidade de São Paulo, São Paulo, SP, Brasil. Recuperado de http://www.teses.usp.br/teses/disponiveis/3/3146/tde-09022009-185405/pt-br.php

Bauer, M., Schwarz, M., \& Mösle, P. (2010). Green Building: Guidebook for Sustainable Architecture. Stuttgart: Springer

Borges, C. A. M., \& Sabbatini, F. H. (2008). O Conceito de Desempenho de Edificações e a sua Importância para o Setor da Construção Civil no Brasil. Boletim Técnico da Escola Politécnica da Universidade de São Paulo. São Paulo. Recuperado de http://citrus.uspnet.usp.br/fau/cursos/pos/areas/area_tecnologia/aut5828/bt515_desempenho_ edificios_borges_sabbatani.pdf

Braga, B., Hespanhol, I., Conejo, L. G. J., Mierzwa, C. J., Barros, L. T. M., Spencer, M., Porto, M., Nucci, N., Juliano, N., \& Eiger, S. (2005). Introdução à Engenharia Ambiental: O desafio do desenvolvimento sustentável. Pearson Pretence Hall. São Paulo

BRASIL. (2010). Lei $n^{0}$ 12.305, de 2 de agosto de 2010. Institui a Política Nacional de Resíduos Sólidos. Recuperado de http://www.planalto.gov.br/ccivil_03/_ato2007-2010/2010/lei//12305.htm BRE Global Ltd. (2010). Scheme Document SD 5055. Recuperado de https://www.hrsservices.co.uk/wp-

content/uploads/2016/07/SD5055_4.0_BREEAM_Offices_2008.pdf

BRE Global Ltd. (2011). Breeam New Construction: Tchecnical Manual. Recuperado de www.breeam.o-rg/breeamCeneralPrint/breeam_non_dom_manual_3_0.pdf

CIB. (2000). Agenda 21 for sustainable construction. CIB World. Recuperado em 29 de maio de 2015, de www.cibworld.nl/website/priority_themes/agenda21.php

Corsani, S. P., Kalbusch, A., \& Ramos, D. A. (2010). Sustentabilidade de edifícios no Brasil: análise do método Alta Qualidade Ambiental - AQUA. Anais do Encontro Nacional de Tecnologia do Ambiente Construído, Canela, RS, Brasil, 13. Recuperado de http://www.infohab.org.br/entac2014/2010/arquivos/599.pdf

Elkington, J. (1994). Towards the sustainable corporation: Win-win-win business strategies for sustainable development. California Management Review, 36(2), p. 90-100. Recuperado de http://journals.sagepub.com/doi/10.2307/41165746?cookieSet=1

Elmualim, A., \& Alp, D. (2016). Perception and Challenges for Sustainable Construction in Developing Countries: North Cyprus Case. Journal of Civil Engineering and Architecture, 10, p.492500. http://www.davidpublisher.org/Public/uploads/Contribute/5722f655ebc47.pdf

FCAV (Fundação Carlos Alberto Vanzolini), \& CERQUAL (Certification Qualité Logement). (2013). Edifícios Habitacionais. Referencial Técnico de Certificação "Edifícios Habitacionais" - Processo AQUA. versão 2. São Paulo: Autores. Recuperado de https://www.vanzolini.org.br/download/RT_Edificios_habitacionais_v2_2013.pdf

Hepper, L. E.; Hansen, P. B. \& Santos, J. L. S. (2016). Iniciativas sustentáveis e desempenho organizacional: uma análise das publicações na Base Web of Science. Revista de Gestão Ambiental e Sustentabilidade-GeAS, 5(2), Mai./Ago., p. 98-114. Recuperado de http://www.revistageas.org.br/ojs/index.php/geas/article/view/410/pdf 
Hill, R. C., \& Bowen, P.A. (1997) Sustainable construction: principles and a framework for attainment. Construction Management and Economics, 15(3), p. 223-239. Recuperado de http://dx.doi.org/10.1080/014461997372971

IDHEA - Instituto para o Desenvolvimento da Habitação Ecológica. (2005). Nove Passos para a Obra Sustentável. Recuperado de www.idhea.com.br/pdf/nove_passos.pdf

Irizarry, J., Zolfagharian, S., Nourbakhsh, M., Zin, R. M., Jusoff, K., \& Zakaria, R. (2012). The development of asustainable-construction planning system. Journal of Information Technology in Construction, 17, p. 162-178. Recuperado de https://www.itcon.org/paper/2012/10

Jagger M. (2011). Certificações e selos verdes. Departamento de Artes e Design. Pontifícia Universidade Católica do Rio de Janeiro, RJ, Brasil. Recuperado de www.pucrio.br/pibic/relatorio_resumo2011/Relatorios/CTCH/DAD/DAD-Michelle\%20Jagger.pdf

John, V. M. (2010). Como obter o Selo Casa Azul. In V. M. John, \& R. T. A. Prado (Orgs.), Boas Práticas Para Habitação Mais Sustentável: Selo Azul da Caixa (p. 20-27). São Paulo: Páginas f Letras.

Recuperado

http://www.cbcs.org.br/userfiles/download/Guia_Selo_Casa_Azul_CAIXA.pdf

John, V. M., \& Prado, R. T. A. (2010). Boas Práticas Para Habitação Mais Sustentável: Selo Azul da Caixa. São Paulo: Páginas \& Letras

Kibert, C. J. (2008). Introduction to sustainable construction. Sustainable Construction. Recuperado de

ftp://ip20017719.eng.ufjf.br/Public/ArtigosCientificosDiversos/ Eficiencia_Energetica\&Conforto_Termico/INTRODUCTION\%20T0\%20SUSTAINBLE\%20CONSTRUC TION.pdf. ISBN 978-0-470-11421-6

Lobo R. V. A. (2010). Ferramenta de Avaliação de Sustentabilidade Ambiental em Edificações Hospitalares na Região Metropolitana de Curitiba (Dissertação de Mestrado). Universidade Federal do Paraná - UFPR, Curitiba, PR, Brasil. Recuperado de https://acervodigital.ufpr.br/handle/1884/24984

Macêdo, A. T., \& Martins, M. F. (2015). A sustentabilidade urbana sob a ótica da construção civil: um estudo nas empresas construtoras de Campina Grande-PB. Journal of Environmental Management and Sustainability - JEMS / Revista de Gestão Ambiental e Sustentabilidade - GeAS, 4, (1), Jan./ Abr., p. 139-157. Recuperado de http://www.revistageas.org.br/ojs/index.php/geas/article/view/183/pdf

Mano, B. E, Pacheco V. A. B. E., \& Bonelli, C. M. C. (2010). Meio Ambiente, Poluição e Reciclagem: São Paulo: Blucher

Meadows, D., Meadows, D., \& Randers, J. (2004). Les limites à la croissance (dans un monde fini). Paris: Editions Rue de l'Echiquier

Mendes G, P. R., Farias M, M. H., \& Tavares, S. F. (2014). Certificação ambiental de habitações: comparação entre LEED FOR HOMES, Processo AQUA e SELO CASA AZUL. Ambiente \& Sociedade, XVII (2), p.195-214. Recuperado de www.redalyc.org/articulo.oa?id=31731560013

Mendes, H. (2013). A construção civil e seu impacto no meio ambiente. Recuperado de http://greendomus.com.br/a-construcao-civil-e-seu-impacto-no-meio-ambiente/

Mihelcic, R. J., \& Zimmermann, B. J. (2012). Engenharia Ambiental: Fundamentos, sustentabilidade e projeto. Rio de Janeiro: LTC

Motta, F. R. S. (2009). Sustentabilidade na Construção Civil: Crítica, Sintese, Modelo de Política e Gestão de Empreendimentos (Dissertação de Mestrado). Universidade Federal de Minas Gerais, 
Belo Horizonte, MG. Recuperado de http://www.bibliotecadigital.ufmg.br/dspace/handle/1843/ISMS-842G7C

Pinto, T. P. (1999). Metodologia para a Gestão Diferenciada de Resíduos Sólidos da Construção Urbana (Tese de Doutorado em Engenharia). Escola Politécnica da Universidade de São Paulo, SP, Brasil. Recuperado de http://www.casoi.com.br/hjr/pdfs/GestResiduosSolidos.pdf

Reed, R., Bilos, A., Wilkinson, S., \& Schulte, K. W. (2009). International Comparison of Sustainable Rating Tools. Journal of Sustainable Real State, 1(1), p. 1-22. Recuperado de https://www.jstor.org/stable/e24860536

Reis, L. T. A, \& Lay, D. C. M. (2010). O projeto da habitação de interesse social e a sustentabilidade local. Ambiente Construido, 10(3), p. 99-119. Recuperado de http://seer.ufrgs.br/index.php/ambienteconstruido/article/viewArticle/12816

Sachs, I. (2007). Rumo à Ecossocioeconomia: Teoria e prática do desenvolvimento. São Paulo: Cortez

Salgado, S. M; Chatelet, A. \& Fernandez, P. (2012). Produção de edificações sustentáveis: desafios e alternativas. Ambiente Construido, 12(4), p. 81-99. Recuperado de http://www.seer.ufrgs.br/ambienteconstruido/article/viewFile/22603/23734

Salgado, M. S. (2008). Projeto integrado: caminho para a produção de edificações sustentáveis: a questão dos sistemas prediais. Anais do Encontro Nacional de Tecnologias do Ambiente Construido, Fortaleza, CE, Brasil, $12 . \quad$ Recuperado de https://www.researchgate.net/publication/268430262_PROJETO_INTEGRADO_-

_CAMINHO_PARA_A_PRODUCAO_DE_EDIFICACOES_SUSTENTAVEIS_a_questao_dos_Sistemas_Pr ediais

Salgado, M. S., \& Lemos, H. (2005). Guidelines for the Certification of Laboratory Architectonic Design, Considering Quality, Environment and Safety Requirements. In World Sustainable Building Conference, Resumo dos trabalhos World Sustainable Building Conference 2005, Tokyo: Autor. Recuperado de https://www.researchgate.net/publication/323075040_Guidelines_for_the_Certification_of_Labor atory_Architectonic_Design_considering_Quality_Environment_and_Safety_Requirements

Santos, H. N., Cândida, A. C., \& Ferreira, T. K. S. (2010) Ações referentes a gestão de resíduos da construção civil em Araguari-MG. In Encontro Nacional dos Geógrafos, Resumo dos trabalhos ENG 2010 (12p.). Porto Alegre: Autor

Saunders, M., Lewis, P., \& Thornhill, A. Research Methods for business sutendents. England: Prentice Hall, 2003

Sebrae - Serviço Brasileiro de Apoio às Micro e Pequenas Empresas (2012). O que pensam as micro e pequenas empresas sobre sustentabilidade. Série de Estudos e Pesquisas, Brasília. Recuperado de http://www.sebrae.com.br/estudos-e-pesquisas

Silva, V. G. (2003). Avaliação da Sustentabilidade de Edifícios de Escritórios Brasileiros: diretrizes e base metodológico (Tese de Doutorado). Escola Politécnica da Universidade de São Paulo, SP, Brasil. Recuperado de https://www.researchgate.net/publication/309187129

Souza, R. (2007). Sustentabilidade nas empresas do setor da construção. Conselho Brasileiro de Construção Sustentável. Recuperado em 21 de abril de 2015, www.cbcs.org.br

Stumpf, U. D., Theis, V., \& Schreiber, D. (2018). Gestão de resíduos sólidos em empresas metalomecânicas de pequeno porte. Journal of Environmental Management and Sustainability -

OS, Organizações e Sustentabilidade, 8(2), p. 34-53, Londrina, PR, jun./dez. 2020.

ISSN 2318-9223, http://www.uel.br/revistas/uel/index.php/ros/issue/view/1683/showToc 
JEMS / Revista de Gestão Ambiental e Sustentabilidade - GeAS, 7, (2), Mai./ Ago., p. 230-247. Recuperado de http://www.revistageas.org.br/ojs/index.php/geas/article/view/598/pdf

Teixeira, M. G., Zamberlam, J. F., Santos, M. B., \& Gomes, C. M. (2016). Processo de mudança para uma orientação sustentável: análise das capacidades adaptativas de três empresas construtoras de Santa Maria-RS. Journal of Environmental Management and Sustainability - JEMS / Revista de Cestão Ambiental e Sustentabilidade - GeAS, 5, (1), Jan./ Abr., p. 45-60. Recuperado de http://www.revistageas.org.br/ojs/index.php/geas/article/view/223/pdf

U.S. Green Building Council. (2009). LEED Reference Guide for Green Building Design and Construction. Recuperado de www.usgbc.org/resources/leed-reference-guide-

World Commission on Environment and Development. (The Brundtland Commission), (1987). Our Common Future. Oxford: Oxford University Press. Recuperado de www.un-documents.net/ourcommon-future.pdf. 